\title{
Development and validation of 'educational pamphlet' in prevention of human papilloma virus (HPV) infection among age eligible adults for HPV vaccination in kedah State, Malaysia
}

\begin{abstract}
Human Papilloma Virus (HPV) infection is highly contagious and affects all males and females at least once in their sexually active lifetime. Though it is spontaneously cured, certain HPV types are responsible for HPV related cancers. This study aimed to develop and evaluate the effectiveness of educational pamphlet in creating awareness regarding HPV infection and vaccination. Main outcome measures include pre-post test assessment of adult's knowledge regarding HPV infection and HPV vaccination, using pre-validated, 16-item knowledge based questionnaire. The pamphlet development, validation and translation was done potential adults aged 18-26 years who were age eligible for HPV vaccination in urban and rural areas of Kedah state, Malaysia. The research findings showed a significant increase in knowledge gain from $63 \%$ to $89 \%$ [N=121, Mdn=10 (IQR=4) to $\mathrm{Mdn}=14(\mathrm{IQR}=3), \mathrm{p}<.001]$ and reveals moderate knowledge and benchmark information before HPV infection and vaccination. At the two-week follow-up, a statistically significant increase in correct responses at prepost-tests were observed at $90 \%,[\mathrm{~N}=92, \mathrm{Mdn}=11 \quad(\mathrm{IQR}=4)$ to $\mathrm{Mdn}=14.5$ (IQR=3), $\mathrm{p}<.001]$. The educational pamphlet significantly increased knowledge regardless of sociodemographic characteristics and was found to be good. Effective, well-structured and informative pamphlets with repeated booster campaigns can help in increasing awareness of HPV infection and awareness among sexually active young adults.
\end{abstract}

Volume 4 Issue I - 2017

\author{
Abdul Nazer Ali, ${ }^{1,3} \mathrm{Ng}$ Yen Ping,' Sunil K \\ Prajapati,' Padmapriya M,' Zulfiker Ahmed \\ Nazer, ${ }^{2}$ Azmi Sarriff ${ }^{3}$ \\ 'AIMST University, Malaysia \\ 'Jawaharlal Nehru Pharma City, India \\ ${ }^{3}$ School of Pharmaceutical Sciences, USM, Malaysia
}

Correspondence: Abdul Nazer Ali, Faculty of Pharmacy, AIMST University, Semeling, 08100, Bedong, Kedah Darul Aman, Malaysia, Tel 006-010-373-026-2, Fax 006-044-298-007, Email abdul.nazeralil6@gmail.com

Received:September 13, 2017 | Published: October 25, 2017

Keywords: adults, educational pamphlet, human papilloma virus, HPV, infection, HPV, vaccine, knowledge

Abbreviations: CDC, centre for disease control; HPV, human papilloma virus; STI, sexually transmitted infection; US, united states; WHO, world health organization

\section{Introduction}

Human papillomavirus (HPV) is one of the most common sexually transmitted infections (STI), and cumulative prevalence rates have been reported up to $82 \%$ in sexually active adolescent and young adults in the United States, ${ }^{1}$ whereas, genital warts are common, in Malaysia but its prevalence has not been determined yet. A commendable knowledge of Human Papilloma Virus (HPV) infection is essential in prevention of HPV related diseases including cancers. The high prevalence and potentially serious complications among sexually active young adults demonstrate a poor understanding of HPV infection, HPV vaccination and Pap tests. ${ }^{2-6}$ It is very unfortunate that the healthcare system of many countries initiated the national HPV vaccination policy for a specific age cohorts (13 years old girls in Malaysia, since 2010) and the other age eligible population (14 to 26 years) were not considered for economic reasons. Presently, the young adults aged 20 years and above are still un-vaccinated though they are eligible for vaccination. There exists a relationship between knowledge and HPV vaccine uptake. The relatively low vaccine uptake in women aged 18-26 years has been reported, thus understanding the factors affecting adult's knowledge on HPV is vital. $^{7}$ The awareness of HPV has been low in the general public. ${ }^{8-11}$ Recent increases in HPV awareness and knowledge are related to the availability of HPV vaccines. Although findings have been mixed, ${ }^{12}$ several studies suggest that greater HPV knowledge is associated with both greater HPV vaccine acceptability ${ }^{13-14}$ and uptake. ${ }^{15,16}$

Of late, WHO recommends 2-doses of HPV vaccine starting before the $15^{\text {th }}$ birthday and the second dose given 6 to 12 months later and a 3-dose regimen is given for 9 through 26-year-old for immuno-compromised including HIV infected..$^{17}$ The current national HPV vaccination programmee in Malaysia has achieved vaccination rate about $87 \%$ per calendar year, 2011 meaning another $13 \%$ leftouts add to the eligible un-vaccinated young adult population. ${ }^{18}$ However, the latest approval of Gardasil 9, offers protection against nine HPV types $-6,11,16,18,31,33,45,52$ and 58 . Seven of which can cause cervical, vulvar and vaginal cancers, as well as anal cancer in both males and females. ${ }^{19-21}$ After HPV types 16 and 18, the five additional HPV types in Gardasil 9 are the most common cervical cancer-causing types globally and in Malaysia, types 52 and 58 are most common in females. ${ }^{22}$ With cervical cancer ranking second most common cancer in Malaysia, there is a great need to increase prevention through vaccination and regular screening. Though, sexually-active women get free pap screening within three years of sexual debut and once every three years subsequently at government hospitals and clinics. ${ }^{22}$ Adequate knowledge is a prerequisite for making informed decisions on vaccination and screening initiatives. ${ }^{23}$ Among the very few intervention studies conducted, simple strategies (providing written materials or verbal information) improved knowledge among adult women..$^{24,25}$ The objective of this study was to evaluate the effectiveness of educational pamphlet developed to fill the gap in literacy by assessing whether such intervention (educational 
pamphlet) could increase the baseline knowledge among age eligible adults.

\section{Materials and methods}

This was a prospective, longitudinal, cross sectional study involving snowball sampling, conducted an HPV education campaign using intervention sessions among young adults aged 18 to 26 years at pre-university/university campus or general public at work places representing both urban and rural population. The content and format of the HPV educational pamphlet was developed in consultation and discussion with a group of five experts from a private medical university involving physicians (Community Medicine, General Medicine, and gynaecologist), an epidemiologist and a practicing clinical pharmacist in Malaysia. The pamphlet was outlined with information that could be easily understood, fairly easy to read and free from jargon's which took roughly 15 minutes to read through and contained the following information: HPV prevalence and transmission, diseases associated, abnormal Pap test, clinical manifestation and complications, risk factors, prevention of HPV related diseases, HPV vaccination, sources of infection and vaccine availability, vaccine course and dosage schedule, side effects, efficacy and safety recommendations. ${ }^{19,26-28}$ The prepared intervention tool was presented for review to the above expert panel and their remarks were accommodated. The tool was then content validated in two sessions by a group of five experts from pharmacology unit, followed by 8 members from clinical pharmacy and pharmacy practice unit from a private university. Readability analysis was performed on the educational intervention tool using well-validated scales that have been commonly used to evaluate healthcare-related materials and to assess the simplicity and readability using online 'Text Readability Consensus Calculator.' The finalized intervention tool was then forward and backward translated to the local Bahasa Malaysia language. The inter-rater reliability was assessed using Cohen kappa test guidelines, which indicated the level of agreement between the two versions of the pamphlet. ${ }^{29-31}$ The finalized intervention tool (pamphlet) was then administered with a specific goal to assess the effectiveness of pamphlet for its readability, understand ability and clarity. The potential respondents were approached for participation in the study for repeated measures of knowledge levels.

The study was conducted using pre-validated questionnaire to assess the baseline knowledge level about HPV infection and HPV vaccination before intervention $(\mathrm{N}=121)$ and educational pamphlets were distributed. The post-intervention test was conducted after two days among the same participants and data was collected for post-test or intervention study (stage $1, \mathrm{~N}=121$ ) to assess knowledge gained due to intervention. Subsequently, a follow-up study after two weeks from intervention, was repeated with pre- post- intervention (stage 2, $\mathrm{N}=92$ ) to assess the knowledge retention among the same respondents. The $24 \%$ drop outs were due to unavailability for participation in the stage 2 study. While generating the knowledge score summary, the correct responses were given ' 1 point' and incorrect responses given 'Zero point.' The numbers of correct items for all the 16 knowledge items were summed to derive the total knowledge score. The scoring grades attributed was based on original Blooms' cut off grades, score $<60 \%$ was 'Poor', $60 \%-79 \%$ 'Moderate', and score $\geq 80 \%$ was considered 'Good'. ${ }^{32-34}$

\section{Statistical analysis}

The survey data was tabulated using Microsoft excel workbook and analyzed using Statistical Package for Social Sciences 'SPSS version-23' (IBM SPSS Statistical software) for windows. The percentage, frequency, median (IQR) score was computed for categorical variables and inferential statistics was done using McNemar's test, to estimate the difference in knowledge scores and Wilcoxon signed rank test to assess the precise difference in knowledge scores. The significance level was set at .05 for all statistical tests and $\mathrm{p}$ value $<.05$ was considered significant. All percentage displayed in the text or in parentheses are with no decimal places as per APA reporting guideline recommendation. ${ }^{35,36}$

\section{Ethical considerations}

The research proposal along with the study instruments and informed consent form was submitted to the Institutional Review Board (IRB), AIMST University Human \& Animal Ethical Committee and the ethical clearance was obtained. The signed informed consent forms were obtained from the participants after explaining the aims and objectives of the study and policy of confidentiality for data collected before filling in the survey forms.

\section{Results}

\section{Readability test}

The text readability of the pamphlet using Flesch reading ease score (69), Flesch-Kincaid grade level (7), and Gunning Fog score (10), were all found to be fairly easy to read and understand.

\section{Agreement of translation between english and malay version}

For inter-rater reliability, Cohen's $\kappa$ was run to determine the agreement between both versions of the educational intervention tool among 30 participants. There was a good agreement between the two versions of the intervention tool as shown in the Table 1.

Table I Agreement between english and malay version of educational pamphlet

\begin{tabular}{|c|c|c|c|c|}
\hline \multicolumn{2}{|l|}{ Variable } & $\begin{array}{l}\text { Concordance } \\
\mathbf{N}(\%)\end{array}$ & \multirow[t]{2}{*}{ k-Value* } & \multirow[t]{2}{*}{ p-Value } \\
\hline \multicolumn{3}{|c|}{ Adults knowledge level } & & \\
\hline \multirow{3}{*}{$(\mathrm{N}=30)$} & Poor & 19 & 0.69 & $<.001^{* *}$ \\
\hline & Moderate & 11 & & \\
\hline & Good & 0 & & \\
\hline
\end{tabular}

*Cohen kappa test statistics, ${ }^{* *} \mathrm{p}<.05$ is significant

\section{Effect of HPV educational intervention tool before and after intervention}

The median (IQR) age of adult respondents $(\mathrm{N}=121)$ in stage 1 was 23 (IQR 2, ranging 20-26) years. Ninety seven (80\%) of the respondents were females, $85(70 \%)$ of the respondents were Chinese, only $2 \%$ of the respondents were married, $66(55 \%)$ revealed undergoing graduate education and 64 (53\%) were from urban areas.

\section{Construct and content validation of HPV educational pamphlet}

The response of 30 potential participants of the intended study was summarized for the entire ten question/statements using four 
point Likert type scale: Strongly Agree -4 points, Agree -3 point; Disagree $=2$ points; and Strongly Disagree $=1$ point. Analysis of the items is shown in Table 2. The correct responses of pre and posteducational intervention test are shown in Table 3. The percentage of correct answers increased significantly from $63 \%$ to $89 \%$ [Mdn. score 10(4) vs. 14(3), p<.001] at stage 1 . However, the percentage of pre- post-knowledge test score increased to $66 \% \& 90 \%$ [Mdn. score 11(4) vs. 14.5(3), $\mathrm{p}<.001]$ at the two-weeks follow-up (Stage 2 ). This result was significantly higher than the pre-educational intervention test $(63 \%)$ at stage 1 , yet was slightly different from the percentage responding correctly at the follow-up visit, showing that the respondents' retention of information over the two weeks' time increased from $63 \%$ to $66 \%$ but was not substantial. Subjective information was gathered for further development of the tool among the survey respondents regarding the contents of the pamphlet.

The results of pre-test reveal the respondents had a moderate knowledge as per original Bloom's cut-off score and benchmark information about HPV infection and HPV vaccination, however were keen to learn more about HPV vaccination and observed the tool to be useful and successful instrument for expanding their knowledge. The question 12 which evaluated the number of vaccination shots produced more than $280 \%$ increase in knowledge and questions 4 which tested gender susceptibility produced over $100 \%$ increase in knowledge and the rest of the questions produced about $60-80 \%$ increase in knowledge. The questions to produce less than $25 \%$ knowledge increase were question numbers $2,5,6,10,14$ and 16 . Most of the respondents were not aware about the best age for HPV vaccination and are mostly affected by HPV infection. The data concerning transmission of HPV vaccination age made a generous impact on the respondents. Statistical analysis of stage 2 revealed that pre-intervention knowledge scores did not contrast by age, gender, race, education or location. Be that as it may, the median knowledge scores at pre-intervention, 11(4) were higher in the age category of 24-26 years in contrast to other age categories. Knowledge scores at post-intervention did not vary by socio-demographic variables. The median age in stage 2 was 23 (IQR 6, range 20-26 years). Of the 92 respondents, 54(59\%) were 21-23 years old, 71(77\%) female, and $66(72 \%)$ Chinese, with $50 \%$ undergraduate education and $47(51 \%)$ belonging to urban areas. The outcome of the pre and posteducational intervention analysis in stage 2 was like those for stage 1 and is shown in Table 3. Though the percentage of knowledge retained only increased marginally from pre-to post-intervention at follow-up visit from $63 \%$ to $66 \%$, the knowledge gained substantially increased from $66 \%$ to $90 \%$ [Mdn. score $=11(4)$ vs. $14.5(3), \mathrm{p}<.001]$. Before accepting the educational intervention, most of the respondents were not aware of the HPV vaccination age.

\section{Discussion}

In this study, an educational intervention tool (pamphlet) was developed, translated and tested to validate the efficiency of the pamphlet in increasing awareness and knowledge regarding HPV infection and HPV vaccination. The intervention tool was found to significantly increase the knowledge and awareness irrespective of age, gender, ethnicity, education and location. The educational pamphlet was developed based on the factual information given by WHO and the CDC along with the vaccine manufacturer's information leaflet. Studies have demonstrated that educational interventions on HPV-related illness effectively increased knowledge along with vaccine acceptability in America, ${ }^{37,38}$ Malaysia, ${ }^{39}$ Korea, ${ }^{40}$ Turkey ${ }^{41,42}$ and Hong Kong. ${ }^{43,44}$ The responses reported in respondents' feedback form were positive. Studies link literacy as an index of positive health outcomes. A study identified literacy and culture as indispensable factors for HPV educational material. ${ }^{45}$ This provides additional challenges related to language and information in the HPV pamphlet for both, educated as well as less educated respondents. The pamphlet was tested for readability and translated to only one language, Bahasa Malaysia, as the study was conducted in Malaysia dominated by the translated literacy. Further, the Cohen's kappa statistic, $\kappa$, was used to measure the agreement between both versions of translation between the two raters. ${ }^{46}$ All were found to be satisfactory with good agreement.

The HPV pamphlet met the appreciation and approval of the participants. More than $90 \%$ indicated the educational tool was acceptable in content, appearance and readability. There was no total disagreement for any item assessed in the evaluation form (Table 2). The final revised pamphlet was colour printed and used for the intervention study. Hence the validation of the pamphlet satisfied the basic requirements. After substantial care was taken in the development of the pamphlet and subjecting it for the various validation studies, the effect of intervention tool (pamphlet) in increasing knowledge regarding HPV infection and HPV vaccination was tested using pre-validated, 16 knowledge based questions. This cross-sectional study was conducted among adults aged $18-26$ years in the rural and urban areas of Sungai Petani, Kedah state, Malaysia. After the intervention, the respondents showed significantly higher awareness and more favorable attitude and beliefs towards prevention of HPV infections. Results endorse that female respondents had better knowledge at baseline. ${ }^{9,47}$ However, similar increase in knowledge was revealed among either genders, whose knowledge seemed to be retained during the 2 -weeks follow-up period. A study in Germany, reported "using a balanced health information leaflet can increase girls' and parents' knowledge of HPV vaccination and its uptake". ${ }^{48}$ Another study reported, a threefold increase in intent to vaccination among college girls using a 20 -minute educational intervention. ${ }^{49}$ After the intervention, the respondents were more tending to practice careful sexual practice with new partner. Results endorse that female respondents had higher knowledge of HPV infection and vaccination at baseline. ${ }^{9,48}$

All studies are investigating the effectiveness of interventions, irrespective of the methods used, aimed at common goals, either to protect from STDs or to improve sexual health. The study also found that prior to intervention; adults had moderate knowledge regarding the cause, transmission, vulnerability, consequences and treatment of HPV. Previous studies reported most young adults have a poor HPV knowledge. ${ }^{25,45,50-52}$ Educational pamphlet developed for this study may be useful for providers to guide patients in clinical setting as well as stake holders in community setting. The possible approaches based on provider and patient for HPV education include the use of pamphlets/brochures or leaflets to reach the large population, providing answers to frequently asked questions. However, those with positive Pap test results or HPV infection would require one-onone education in a clinical setting. A few people prefer information from providers due to privacy. ${ }^{53}$ Proper education intervention like this can be used as the first-line approach in preventing HPV related infection and illness. Our study results provide new information on effectiveness of educational pamphlets among the respondents regarding HPV infection and vaccination. 
Table 2 Tabulation for HPV pamphlet evaluation response

\begin{tabular}{|c|c|c|c|c|c|c|}
\hline No. & Questions & SA & $\mathbf{A}$ & DA & SD & p value \\
\hline I & Evaluate the appearance of the pamphlet & $12(40)$ & II (37) & $7(23)$ & $0(0)$ & 0.497 \\
\hline 2 & Is the front of the alphabets appropriate? & $23(77)$ & $5(17)$ & $2(7)$ & $0(0)$ & $<.001 *$ \\
\hline 3 & Is the content on HPV infection easy to read and understand & 17 & 11 & 2 & 0 & $.003^{*}$ \\
\hline 4 & Is the content on the Pap Smear easy to read and understand & 16 & 13 & I & 0 & $.002 *$ \\
\hline 5 & Is the content on the age of HPV vaccine easy to read and understand & 18 & 12 & 0 & 0 & 0.273 \\
\hline 6 & Is the content on the dose of HPV vaccine easy to read and understand & 22 & 8 & 0 & 0 & $.011^{*}$ \\
\hline 7 & $\begin{array}{l}\text { Is the content on the dose frequency of HPV vaccine easy to read and } \\
\text { understand }\end{array}$ & 17 & 12 & I & 0 & $.001 *$ \\
\hline 8 & Is the content on the availability of HPV vaccine easy to read and understand & 17 & 13 & 0 & 0 & 0.465 \\
\hline 9 & Would you take the pamphlet home to read later & 18 & 12 & 0 & 0 & 0.273 \\
\hline 10 & Will you get HPV vaccinated for yourself or your child & $14(47)$ & $13(43)$ & $3(10)$ & $0(0)$ & $.025 *$ \\
\hline
\end{tabular}

SA: Strongly agree;A:Agree; DA: Disagree; SD: Strongly disagree

$*$ Chi square test, $\mathrm{p}<.05$ is significant.

Table 3 Proportion of Correct Responses to knowledge based questions, before and after Intervention among Adults

\begin{tabular}{|c|c|c|c|c|c|c|c|}
\hline \multirow[t]{2}{*}{ No. } & \multirow[t]{2}{*}{ Knowledge items of adults } & \multicolumn{3}{|c|}{$\begin{array}{l}\text { Stage I of intervention tool development } \\
(\mathbf{N}=121)\end{array}$} & \multicolumn{3}{|c|}{$\begin{array}{l}\text { Stage } 2 \text { of intervention tool } \\
\text { development }(\mathbf{N}=92)\end{array}$} \\
\hline & & Pre-test N (\%) & $\begin{array}{l}\text { Post-test N } \\
\text { (\%) }\end{array}$ & p value & $\begin{array}{l}\text { Pre- } \\
\text { test N } \\
(\%)\end{array}$ & $\begin{array}{l}\text { Post-test } \\
\text { N (\%) }\end{array}$ & p value \\
\hline I & $\begin{array}{l}\text { HPV infection affects skin and the moist } \\
\text { membranes that line the human body. }\end{array}$ & $63(52)$ & $108(89)$ & $<.00 I^{*}$ & $49(53)$ & $81(88)$ & $<.00 \mathrm{I}^{*}$ \\
\hline 2 & $\begin{array}{l}\text { I came to know about HPV infection through } \\
\text { advertisements (radio, TV, internet)/ friends/ } \\
\text { parents/ teachers). }\end{array}$ & $96(79)$ & $109(90)$ & $.037^{*}$ & $75(82)$ & $82(89)$ & 0.23 \\
\hline 3 & HPV can infect males, females or both. & $73(60)$ & $108(89)$ & $<.001 *$ & $58(63)$ & $80(87)$ & 0.405 \\
\hline 4 & HPV infects mostly females. & $53(44)$ & $108(89)$ & $<.001 *$ & $36(39)$ & $81(88)$ & $<.001 *$ \\
\hline 5 & $\begin{array}{l}\text { Women infected with HPV are more likely to } \\
\text { get cancer of the cervix. }\end{array}$ & $95(79)$ & $108(89)$ & $.037^{*}$ & $73(79)$ & $81(88)$ & 0.152 \\
\hline 6 & $\begin{array}{l}\text { Those infected with HPV are more likely to } \\
\text { get pelvic warts, genital warts, penile cancer, } \\
\text { cervical cancer and some other less common } \\
\text { cancers. }\end{array}$ & 91 (75) & $102(84)$ & 0.109 & $57(62)$ & $83(90)$ & $<.00 I^{*}$ \\
\hline 7 & $\begin{array}{l}\text { Most people who are infected with HPV } \\
\text { do not know that they are infected. }\end{array}$ & $75(62)$ & $106(88)$ & $<.001 *$ & $53(58)$ & $81(88)$ & $<.00 I^{*}$ \\
\hline 8 & $\begin{array}{l}\text { Signs and symptoms of HPV infection will take } \\
\text { few months to years for developing. }\end{array}$ & $68(56)$ & $107(88)$ & $<.00 I^{*}$ & $52(57)$ & $83(90)$ & $<.00 I^{*}$ \\
\hline 9 & $\begin{array}{l}\text { Mostly, HPV infection is transmitted through } \\
\text { sexual intercourse. }\end{array}$ & $65(54)$ & $108(89)$ & $<.001 *$ & $78(85)$ & $85(92)$ & 0.189 \\
\hline 10 & $\begin{array}{l}\text { A vaccine is a biological preparation that } \\
\text { improves immunity against a particular disease. }\end{array}$ & 95 (79) & 107 (88) & $.045^{*}$ & $69(75)$ & $83(90)$ & $.018^{*}$ \\
\hline II & $\begin{array}{l}\text { The HPV vaccination prevents HPV infection- } \\
\text { associated development of cervical cancer, } \\
\text { penile cancer, genital warts, and some less } \\
\text { common cancers. }\end{array}$ & $83(69)$ & 106 (88) & $.001 *$ & $56(6 I)$ & $84(91)$ & $<.001 *$ \\
\hline
\end{tabular}


Table Continued...

\begin{tabular}{|c|c|c|c|c|c|c|c|}
\hline \multirow[t]{2}{*}{ No. } & \multirow[t]{2}{*}{ Knowledge items of adults } & \multicolumn{3}{|c|}{$\begin{array}{l}\text { Stage I of intervention tool development } \\
(N=12 I)\end{array}$} & \multicolumn{3}{|c|}{$\begin{array}{l}\text { Stage } 2 \text { of intervention tool } \\
\text { development }(\mathbf{N}=92)\end{array}$} \\
\hline & & Pre-test N (\%) & $\begin{array}{l}\text { Post-test N } \\
\text { (\%) }\end{array}$ & p value & $\begin{array}{l}\text { Pre- } \\
\text { test N } \\
(\%)\end{array}$ & $\begin{array}{l}\text { Post-test } \\
\text { N (\%) }\end{array}$ & p value \\
\hline 12 & $\begin{array}{l}\text { The course of the HPV vaccination comprises of } \\
\text { one, two or three doses. }\end{array}$ & $29(24)$ & $113(93)$ & $.003^{*}$ & $70(76)$ & $85(92)$ & $<.00 I^{*}$ \\
\hline 13 & $\begin{array}{l}\text { The best age for HPV vaccination is between } \\
9-14,15-20 \text { or } 21-26 \text { years. }\end{array}$ & 71 (59) & $108(89)$ & $<.001 *$ & $67(73)$ & $84(91)$ & $.009 *$ \\
\hline 14 & $\begin{array}{l}\text { The HPV vaccination can be given from the age } \\
\text { of } 9 \text { to } 26 \text { years. }\end{array}$ & $94(78)$ & $108(89)$ & $<.001 *$ & $49(53)$ & $83(90)$ & $.005^{*}$ \\
\hline 15 & $\begin{array}{l}\text { Pap smear test can be used to screen pelvic } \\
\text { cancer, cervical cancer or oral cancer. }\end{array}$ & $63(52)$ & $102(84)$ & $.026 *$ & $58(63)$ & $82(89)$ & $<.001 *$ \\
\hline 17 & Total Median Score & $10(4)$ & $14(3)$ & $<.001+$ & II (4) & $14.5(3)$ & $<.001+$ \\
\hline \multicolumn{2}{|c|}{ Percentage of correct answers } & $63 \%$ & $89 \%$ & & $66 \%$ & $90 \%$ & \\
\hline
\end{tabular}

*McNemar's Test; $\mathrm{p}<.05,+$ Wilcoxon Signed Rank Test; $\mathrm{p}<.05$ is significant

\section{Conclusion}

In conclusion, the results presented in this study give an insight into the effects of educational pamphlet in improving knowledge among adult population regarding HPV infection and HPV vaccination. This study results confirm that educational initiatives have proven to improve awareness and enhance beliefs for appropriate practice towards HPV prevention. Therefore, in addition to providing clear, precise and tailored information regarding implications of HPV infection, addressing misconceptions of vaccination, its prevention, fears of pap screening, vaccine side effects and vaccination is of utmost importance. Further, a comprehensive and sustainable HPV and cervical cancer education should be incorporated into health education from the early teen-ages in order to achieve the desired outcome.

\section{Acknowledgements}

We would like to express my deepest gratitude to all of the participants for their time, cooperation, support and patience that have been given during the repeated data collection exercise.

\section{Conflict of interest}

None declared.

\section{References}

1. Brown DR, Shew ML, Qadadri B, et al. A longitudinal study of genital human papillomavirus infection in a cohort of closely followed adolescent women. J Infect Dis. 2005;191(2):182-192.

2. Yacobi E, Tennant C, Ferrante J, et al. University students' knowledge and awareness of HPV. Prev Med. 1999;28(6):535-541.

3. Dell DL, Chen H, Ahmad F, et al. Knowledge about human papillomavirus among adolescents. Obstet Gynecol. 2000;96(5 Pt 1):653-656.

4. Gerhardt CA, Pong K, Kollar LM, et al. Adolescents' knowledge of human papillomavirus and cervical dysplasia. J Pediatr Adolesc Gynecol. 2000;13(1):15-20.

5. Waller J, McCaffery K, Nazroo J, et al. Making sense of information about HPV in cervical screening: a qualitative study. $\mathrm{Br} \mathrm{J}$ Cancer 2005;92(2):265-270.
6. Blake DR, Weber BM, Fletcher KE. Adolescent and young adult women's misunderstanding of the term Pap smear. Arch Pediatr Adolesc Med. 2004;158(10):966-970.

7. Gerend MA, Shepherd JE. Correlates of HPV knowledge in the era of HPV vaccination: a study of unvaccinated young adult women. Women Health. 2011;51(1):25-40.

8. Gerend MA, Magloire ZF. Awareness, knowledge, and beliefs about human papillomavirus in a racially diverse sample of young adults. $J$ Adolesc Health. 2008;42(3):237-242.

9. Klug SJ, Hukelmann M, Blettner M. Knowledge about infection with human papillomavirus: a systematic review. Prev Med. 2008;46(2):87-98.

10. Sandfort JR, Pleasant A. Knowledge, attitudes, and informational behaviours of college students in regard to the human papillomavirus. $J \mathrm{Am}$ Coll Health. 2009;58(2):141-149.

11. Tiro JA, Meissner HI, Kobrin S, et al. What do women in the US know about human papillomavirus and cervical cancer? Cancer Epidemiol Biomarkers Prev. 2007;16(2):288-294.

12. Brewer NT, Fazekas KI. Predictors of HPV vaccine acceptability: a theory-informed, systematic review. Prev Med. 2007;45(2):107-114.

13. Jones M, Cook R. Intent to receive an HPV vaccine among university men and women and implications for vaccine administration. J Am Coll Health. 2008;57(1):23-32.

14. Woodhall SC, Lehtinen M, Verho T, et al. Anticipated acceptance of HPV vaccination at the baseline of implementation: a survey of parental and adolescent knowledge and attitudes in Finland. Journal J Adolesc Health. 2007;40(5):466-469.

15. Licht AS, Murphy JM, Hyland AJ, et al. Is use of the human papillomavirus vaccine among female college students related to human papillomavirus knowledge and risk perception? Sex Transm Infect. 2010;86(1):74 78

16. Mathur MB, Mathur VS, Reichling DB. Participation in the decision to become vaccinated against human papillomavirus by California high school girls and the predictors of vaccine status. J Pediatr Health Care. 2010;24(1):14-24. 
17. Meites E, Kempe A, Markowitz LE. Use of a 2-dose schedule for human papillomavirus vaccination-updated recommendations of the Advisory Committee on Immunization Practices. MMWR Morb Mortal Wkly Rep. 2016;65(49):1405-1408

18. Bruni L, Barrionuevo-Rosas L, Albero G, et al. ICO Information Centre on HPV and Cancer (HPV Information Centre). Human papillomavirus and related diseases in India. Summary Report. 2017;12-23.

19. Markowitz LE, Dunne EF, Saraiya M, et al. Human papillomavirus vaccination: recommendations of the Advisory Committee on Immunization Practices (ACIP). Centers for Disease Control and Prevention (CDC), MMWR Recomm Rep. 2014;63(RR-05):1-30.

20. Petrosky E, Bocchini JA, Hariri S, et al. Use of 9-valent human papillomavirus (HPV) vaccine: updated HPV vaccination recommendations of the advisory committee on immunization practices. Centers for Disease Control and Prevention (CDC). MMWR Morb Mortal Wkly Rep. 2015;64(11):300-304

21. Viens LJ, Henley SJ, Watson M, et al. Human Papillomavirus-Associated Cancers-United States, 2008-2012. MMWR Morb Mortal Wkly Rep 2016;65(26):661-666

22. http://www.thestar.com.my/news/nation/

23. Abraham C, Michie S. A taxonomy of behaviour change techniques used in interventions. Health Psycho. 2008;27(3):379-387.

24. Malo TL, Giuliano AR, Kahn JA, et al. Physician's human papillomavirus vaccine recommendations in the context of permissive guideline for male patients: a national study. Cancer Epidemiol Biomarkers Prev. 2014;23(10):2126-2135

25. Gottvall M, Tydén T, Höglund AT, et al. Knowledge of human papillomavirus among high school students can be increased by an educational intervention. Int J STD AIDS. 2010;21(8):558-562.

26. Wetzel C, Tissot A, Kollar LM, et al. Development of an HPV educational protocol for adolescents. J Pediatr Adolesc Gynecol. 2007;20(5):281287

27. Cervical cancer rates by race and ethnicity. Centers for Disease Control and Prevention. USA; 2011

28. Cassidy B, Braxter B, Charron-Prochownik D, et al. A quality improvement initiative to increase HPV vaccine rates using an educational and reminder strategy with parents of preteen girls. $J$ Pediatr Health Care. 2014;28(2):155-164.

29. McHugh ML. Interrater reliability: the kappa statistic. Biochem Med (Zagreb). 2012;22(3):276-282.

30. Stemler SE, Tsai J. Best practices in interrater reliability: Three common approaches. Best practices in quantitative methods. 2008:29-49.

31. Viera AJ, Garrett JM. Understanding interobserver agreement: the kappa statistic. Fam Med. 2005;37(5):360-363.

32. Nahida A. Knowledge Attitude and Practice on Dengue Fever, Thesis for Masters in Public Health. College of Public Health Sciences: Chulalongkorn University, Thiland; 2007.

33. Kaliyaperumal K. Guideline for Conducting a Knowledge, Attitude and Practice (KAP) Study. AECS Illumination. 2004;4(1):1-9.

34. John J. The knowledge, attitude, practice and perceived barriers towards screening for premalignant cervical lesions among women aged 18 years and above, in Songea urban, Ruvuma. USA: Muhimbili University of health and allied sciences, Tanzania; 2011. p. 1-87.

35. Kahn J. Reporting statistics in APA style. USA: Illinois State University; 2017.
36. Hesson-McKinnis M. Reporting statistics in APA Style. USA: Washington; 2014

37. Reiter PL, Stubbs B, Panozzo CA, et al. HPV and HPV vaccine education intervention: effects on parents, healthcare staff, and school staff. Cancer Epidemiol Biomarkers Prev. 2011;20(11):2354-2361.

38. Hopfer S. Effects of a narrative HPV vaccination intervention aimed at reaching college women: a randomized controlled trial. Prev Sci. 2012;13(2):173-182

39. Zaridah S. A review of cervical cancer research in Malaysia. Med J Malaysia. 2014;69(Suppl A):33-41.

40. Oh JK, Lim MK, Yun EH, et al. Awareness of and attitude towards human papillomavirus infection and vaccination for cervical cancer prevention among adult males and females in Korea: a nationwide interview survey. Vaccine. 2010;28(7):1854-1860.

41. Uzunlar Ö, Özyer Ș, Bașer E, et al. A survey on human papillomavirus awareness and acceptance of vaccination among nursing students in tertiary hospital in Ankara, Turkey. Vaccine. 2013;31(17):2191-2195.

42. Tonguc E, Gungor T, Var T, et al. Knowledge about HPV, relation between HPV and cervix cancer and acceptance of HPV vaccine in women in eastern region of Turkey. J Gynecol Oncol. 2013;24(1):7-13.

43. Kwan TT, Lo SS, Tam KF, et al. Assessment of knowledge and stig matizing attitudes related to human papillomavirus among Hong Kong Chinese healthcare providers. Int J Gynaecol Obstet. 2012;116(1):52-56.

44. Kwan TT, Tam KF, Lee PW, et al. The effect of school-based cervical cancer education on perceptions towards human papillomavirus vaccination among Hong Kong Chinese adolescent girls. Patient Educ Couns 2011;84(1):118-122.

45. Sharpe PA, Brandt HM, McCree DH, et al. Development of culturally tailored educational brochures on HPV and Pap tests for American Indian women. J Transcult Nurs. 2013;24(3):282-290.

46. Cohen EL, Head KJ. Identifying knowledge-attitude-practice gaps in parental acceptance of adolescent vaccinations in Appalachian Kentucky: Implications for communication interventions. Journal of Communication in Healthcare. 2014;7(4):295-302.

47. Baer H, Allen S, Braun L. Knowledge of human papillomavirus infection among young adult men and women: implications for health education and research. J Community Health. 2000;25(1):67-78.

48. Wegwarth O, Kurzenhäuser-Carstens S, Gigerenzer G. Overcoming the knowledge-behavior gap: the effect of evidence-based HPV vaccination leaflets on understanding, intention, and actual vaccination decision. Vaccine. 2014;32(12):1388-1393.

49. Gross MS, Tran CH, Sutherland KH, et al. Pilot Study: Can an educational intervention increase human papillomavirus vaccination in female college students? Obstetrics \& Gynecology. 2014;123:S114-S115.

50. Shepherd J, Weston R, Peersman G, et al. Interventions for encouraging sexual lifestyles and behaviours intended to prevent cervical cancer. $\mathrm{Co}$ chrane Database Syst Rev. 1999;2000(2):CD001035.

51. Dempsey AF, Zimet GD, Davis RL, et al. Factors that are associated with parental acceptance of human papillomavirus vaccines: a randomized intervention study of written information about HPV. Pediatrics. 2006;117(5):1486-1493.

52. Warren K. HPV knowledge among female college students and the short term effectiveness of HPV education. The Internet Journal of Academic Physician Assistants. 2010;7(2).

53. McCree DH, Sharpe PA, Brandt HM, et al. Preferences for sources of information about abnormal Pap tests and HPV in women tested for HPV. Preventive medicine. 2006;43(3):165-170. 